Relations industrielles

Industrial Relations

\title{
Statistiques syndicales
}

Volume 6, numéro 1, décembre 1950

URI : https://id.erudit.org/iderudit/1023249ar

DOI : https://doi.org/10.7202/1023249ar

Aller au sommaire du numéro

Éditeur(s)

Département des relations industrielles de l’Université Laval

\section{ISSN}

0034-379X (imprimé)

1703-8138 (numérique)

Découvrir la revue

Citer cet article

(1950). Statistiques syndicales. Relations industrielles / Industrial Relations, 6(1),

29-29. https://doi.org/10.7202/1023249ar

Tous droits réservés @ Département des relations industrielles de l’Université Laval, 1950
Ce document est protégé par la loi sur le droit d'auteur. L’utilisation des services d'Érudit (y compris la reproduction) est assujettie à sa politique d'utilisation que vous pouvez consulter en ligne.

https://apropos.erudit.org/fr/usagers/politique-dutilisation/ 


\section{Statistiques syndicales}

Le relevé annuel du ministère du Travail sur le syndicalisme ouvrier indique qu'au 81 décembre 1949, le Canada comptait 5,268 unités locales couvrant 1,005,639 syndiqués. L'inclusion de Terreneuve ajoute quelque 24,000 membres à l'effectif syndical global.

Voici comment ce million d'ouvriers syndiqués se répartit. L'effectif du Congrès des Métiers et du Travail du Canada, lequel groupe 2,805 unités locales de syndicats affiliés ou à charte directe, s'établit à 459,068 membres. La Fédération américaine du travail compte 29 unités canadiennes qui lui sont directement rattachées. Ces unités comprennent 13,996 membres. Le Congrès canadien du travail avec ses 1,175 unités locales comprend 301,729 membres. Le Congrès des organisations industrielles des Etats-Unis, a 53 unités locales canadiennes qui lui sont attachées avec 27,475 membres. La Confédération des travailleurs catholiques du Canada compte 424 unités locales couvrant 80,089 membres. Les Fraternités internationales de travailleurs ferroviaires (indépendantes) ont 382 unités locales et 41,363 membres. La Fédération canadienne du travail compte 3,872 membres répartis dans 7 unités. Le Conseil national du travail a 3,451 membres dans 17 unités. Il y a aussi un certain nombre de syndicats nationaux et internationaux non affiliés qui comptent 255 unités locales et 57,923 membres. Enfin des syndicats locaux non affiliés comptent 61 unités et 16,673 membres. ${ }^{1}$

(1) Information tirée du Communiqué du Ministère fédéral du travail, du 20 septembre 1950.

\section{UN TEMOIGNAGE}

\section{MINISTERE DU TRAVAIL MANITOBA}

3 novembre 1950.

M. Gérard Tremblay, Directeur,

Département des relations industrielles, Université Laval,

Québec.

Cher monsieur Tremblay,

Je suis très heureux de l'occasion que me fournit la réception de votre circulaire du 20 octobre, de vous écrire en votre qualité de directeur du Département des relations industrielles.

Je lis presque religieusement le Bulletin des relations industrielles en pensant que sa façon d'exposer les problèmes de relations industrielles au Canada est à la fois nouvelle et constructive.

Je puis dire que j'ai recommandé le Bulletin aux avocats du Manitoba et aux administrateurs de la législation du travail comme pouvant leur donner un aperçu inestimable des problèmes auxquels ils ont à faire face.

Aussi, je suis très intéressé dans l'annonce que votre nouvelle revue paraîtra tous les trois mois et qu'elle contiendra soixante pages de matière originale, constituant une étude inédite et complète d'un suiet en rapport direct avec les relations industrielles.

La présentation bilingue de votre Bulletin a un intérêt particulier pour moi, car cela m'aide à conserver mes connaissances du français. De toute manière lorsque je suis arrêté par un mot, je puis toujours référer à la version anglaise.

Je voudrais vous féliciter pour la haute tenue que votre Bulletin a constamment maintenue et vous souhaiter tout le success possible dans la nouvelle entreprise qui verra le Bulletin devenir trimestriel d'une manière assez prodigieuse.

Avec mes meilleurs souhaits personnels, je suis,

Sincèrement vôtre,

W. Elliot Wilson, Sous-ministre du travail.
C'est l'homme qui honore sa position et non la position qui honore l'homme.

Pasteur
Si vous voulez qu'un de vos seconds soit un chef, ne le traitez pas en esclave.

Detoeuf

La vie toute entière dun homme dépend de deux ou trois oui et de deux ou trois non, prononcés de 16 d 20 ans.
L'autorité est un service: elle n'est pas faite pour mutiler la personnalité des exécutants mais pour laider d grandir. 